\title{
Reflexos da utilização de farelo de coco sobre o valor nutricional do filé de tilápia-do-nilo (Oreochromis niloticus Linnaeus, 1857)
}

\author{
The impact of the use of coconut meal on the nutritional value \\ of the nile tilapia (Oreochromis niloticus Linnaeus, 1857)
}

\begin{abstract}
Cristhiane Maria Bazílio de OMENA ${ }^{1 \star}$, Maria Emília da Silva MENEZES $^{1}$, Cenira Monteiro de CARVALHO ${ }^{1}$, Jaqueline Maria da SILVA ${ }^{1}$, Maria Beatriz Farias de OLIVEIRA ${ }^{1}$, Edma Carvalho de MIRANDA ${ }^{1}$, Denise Maria PINHEIRO ${ }^{1}$, Severino Matias de ALENCAR², Antônio Euzébio Goulart SANT'ANA ${ }^{1}$
\end{abstract}

\section{Resumo}

O uso do farelo de coco pode representar uma fonte alternativa na alimentação de peixe. Por esse motivo avaliaram-se os reflexos de sua utilização sobre o valor nutricional do filé de tilápia-do-nilo. O experimento foi realizado em um delineamento inteiramente ao acaso com 4 tratamentos (T1 - 0\%, T2 - 10\%, T3 - 20\% e T4 - 30\% de inclusão de farelo de coco) e cinco repetições. Foram determinados a composição centesimal, o teor de colesterol e os teores de ácidos graxos. Observou-se diferença $(\mathrm{p}<0,05)$ entre T1 e T3, T2 e T3 para os teores de umidade; entre T2 e T3 para os lipídios; T1 apresentou diferença com relação aos demais tratamentos referentes aos carboidratos; e quanto aos teores de cinzas foi observada diferença de T1 e T2 entre T3 e T4. Os teores de colesterol apresentaram um aumento gradual significativo. Com relação aos ácidos graxos, observou-se diferença $(\mathrm{p}<0,05)$ entre os tratamentos referentes aos $\mathrm{C}_{10: 0} ; \mathrm{C}_{12: 0} ; \mathrm{C}_{14: 0} ; \mathrm{C}_{18: 1} ; \mathrm{C}_{18: 3}\left(\right.$ gama); $\mathrm{C}_{20: 3} ;$ e $\mathrm{C}_{22: 6}$ numa proporção tal que não determinou diferença na qualidade nutricional do produto.

Palavras-chave: tilápia; farelo de coco; ácidos graxos; colesterol; Oreochromis niloticus Linnaeus.

\begin{abstract}
The use of coconut meal may represent an alternative source to fish feeding. The purpose of this work was to assess the impact of the use of coconut meal in Nile tilapia feeding and on the nutritional value of the fish fillets. The experiment was conducted in a completely randomized design with 4 treatments (T1 - 0\%, T2 - 10\%, T3 - 20\%, and T4-30\% for the inclusion of coconut meal) with five repetitions. The proximate composition, cholesterol, and fatty acids were determined. There was a difference $(\mathrm{p}<0.05)$ between the treatments T1 and T3 and between T2 and T3 with regard to moisture levels; between T2 and T3 with regard to lipids; T1 and all the other treatments with regard to carbohydrates, and finally between $\mathrm{T} 1$ and $\mathrm{T} 2$ and between $\mathrm{T} 3$ and $\mathrm{T} 4$ with regard to ash. The cholesterol level showed a significant gradual increase following the increase in the inclusion of coconut meal. There was also a difference $(\mathrm{p}<0.05)$ between the treatments concerning the following fatty acids: $\mathrm{C}_{10: 0} ; \mathrm{C}_{12: 0} ; \mathrm{C}_{14: 0} ; \mathrm{C}_{18: 1} ; \mathrm{C}_{18: 3}$ (gama); $\mathrm{C}_{20: 3}$ and $\mathrm{C}_{22: 6}$, but the nutritional quality of the product was not affected.

Keywords: tilapia; coconut meal; fatty acids; cholesterol; Oreochromis niloticus Linnaeus.
\end{abstract}

\section{Introdução}

As tilápias são ciclídeos originários do continente africano e apresentam produção concentrada principalmente em regiões de clima tropical e subtropical. São reconhecidas mais de 70 espécies de tilápias, sendo três os principais gêneros de importância comercial: Oreochromis spp., Sarotherodon spp. e Tilapia spp. (NOVA; GODOY; ALDRIGUE, 2005). O nome tilápia, utilizado pela primeira vez por Smith em 1940, é um vocábulo africano e significa "PEZ" pronunciando-se [t $u$ läpE $u$ ] (CAMPO, 2006).

$\mathrm{Na}$ aquicultura mundial, as tilápias são classificadas como o segundo grupo de peixes de maior importância. Dentre os fatores envolvidos na escolha desse peixe estão o crescimento rápido, a rusticidade e a ótima qualidade da carne (BOSCOLO; HAYASHI; MEURER, 2002; SOUZA et al., 2004).
A carne da tilápia possui boas características organolépticas. Este peixe apresenta a carne sem espinhos intramusculares, de cor branca, textura firme, aspecto fibroso e suculento, sabor apreciável e elevado valor nutricional (SOUZA; MARANHÃO, 2001). Por não apresentar espinhos na forma de "Y" no seu filé, é apropriada para a filetagem. Possui um rendimento em filé de aproximadamente $33 \%$ e a comercialização é realizada quando os espécimes atingem de 350 a $1000 \mathrm{~g}$, dependendo da sua utilização (ALBUQUERQUE; ZAPATA; ALMEIDA, 2004; BOSCOLO; HAYASHI; MEURER, 2002; FURUYA et al., 2001). A espécie é recomendada para o consumo fresco, desidratado, salgado ou defumado (LEONHARDT et al., 2006).

Os peixes apresentam proteínas de elevado valor biológico e a gordura destaca-se pela composição em ácidos graxos de valor

Recebido para publicação em 17/6/2008

Aceito para publicação em 20/6/2009 (003545)

Instituto de Química e Biotecnologia, Universidade Federal de Alagoas - UFAL, Campus A. C. Simões, Tabuleiro dos Martins, CEP 57072-970, Maceió - AL, Brasil, E-mail: crisbomena@hotmail.com

2 Departamento de Agroindústria, Alimentos e Nutrição, Escola Superior de Agricultura "Luiz de Queiroz", Universidade de São Paulo - USP, Piracicaba - SP, Brasil

${ }^{*}$ A quem a correspondência deve ser enviada 
nutricional para os seres humanos (SOUZA et al., 2005). O pescado é de extrema importância na dieta alimentar por sua riqueza de nutrientes, alto teor proteico, contendo uma composição de aminoácidos equilibrada, lipídios de excelente qualidade e baixo teor de colesterol (NOVA; GODOY; ALDRIGUE, 2005).

A dieta alimentar dos peixes exerce um fator decisivo sobre a composição do tecido muscular e, especialmente, sobre a composição de ácidos graxos desse tecido. Os ácidos graxos de peixes diferem e, dentre os fatores responsáveis por essa variabilidade, estão a bioquímica do metabolismo dos ácidos graxos essenciais e a composição da dieta nos dois habitats. Os ácidos graxos derivados da dieta são transferidos, metabolizados, armazenados e/ou transformados em outros ácidos. Estudos demonstraram que peixes de cativeiro, alimentados exclusivamente com rações comerciais, apresentaram baixos teores de AGPI $\omega-3$ quando comparados com espécies nativas (RIBEIRO; HAYASHI; FURUYA, 1995).

As rações utilizadas no cultivo de peixes de água doce são constituídas de diferentes fontes dos farelos e óleos de origem animal e vegetal. Devido à diversidade da origem dos ingredientes, é de fundamental importância o conhecimento da influência destes sobre o filé, que é a parte consumida pela população. Os dados ligados à composição da carne de peixe são também importantes no processo de conservação e elaboração de produtos derivados dos peixes, pois um fator de grande influência sobre tais processos é a quantidade de ácidos graxos insaturados, que propiciam alterações nestes produtos, como oxidação (SANTOS et al., 2000).

No nordeste brasileiro, entre os alimentos alternativos, pode-se destacar o farelo ou torta de coco, subproduto obtido da extração do óleo. De acordo com a FAO (FOOD..., 2003), 1000 frutos produzem, em média, $180 \mathrm{Kg}$ de copra (polpa do coco ou amêndoa seca), cujo processamento rende, aproximadamente, $110 \mathrm{Kg}$ de azeite e $55 \mathrm{Kg}$ de farelo; sendo o restante $(15 \mathrm{Kg})$ evaporado. A utilização do farelo de coco pode ser economicamente viável em áreas em que a disponibilidade no mercado de outras fontes de proteínas de qualidade seja escassa (BRAGA et al., 2005).

O objetivo do presente trabalho foi avaliar os reflexos da utilização de farelo de coco na alimentação de tilápia-do-nilo
(Oreochromis niloticus Linnaeus, 1857) sobre o valor nutricional do filé.

\section{Material e métodos}

\subsection{Peixes}

Foram utilizados 120 machos revertidos de tilápiado-nilo, com peso vivo médio inicial de 10,3 $\pm 1,76 \mathrm{~g}$, distribuídos em 20 caixas de polietileno de forma homogênea; contendo 6 exemplares por caixa; com uma temperatura de aproximadamente $27,5 \pm 0,8^{\circ} \mathrm{C}$. Os peixes foram mantidos nos aquários de alimentação durante 90 dias, onde receberam ração à vontade (aproximadamente $7 \mathrm{~g}$ por tanque, aumentando de acordo com a fase de crescimento do animal), três vezes ao dia (8, 12 e 17 horas).

O experimento foi realizado em bloco inteiramente casualizado com 4 tratamentos em diferentes níveis de farelo de coco - T1 (0\%), T2 (10\%), T3 (20\%) e T4 (30\%) -; cada tratamento com 5 repetições. No término do experimento, foram retirados aleatoriamente, para análises, 2 indivíduos de cada tanque, totalizando 10 amostras por tratamento.

Após os 90 dias, os peixes foram submetidos a um choque térmico (abate) em caixa isotérmica com gelo e água. Na retirada do filé, o peixe foi decapitado e eviscerado, removeram-se as nadadeiras dorsal, anal e a pele. O filé foi obtido a partir da musculatura dorsal, nas duas nadadeiras do sentido longitudinal, ao longo de toda a extensão da coluna vertebral e costelas. Os filés dos exemplares foram removidos e imediatamente acondicionados em sacos plásticos devidamente etiquetados e mantidos sobre congelamento a $-18{ }^{\circ} \mathrm{C}$, até o início das análises.

\subsection{Preparo das rações}

As rações experimentais eram isoproteicas e isoenergéticas

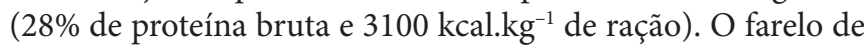
coco substituiu parcialmente o ingrediente convencional (farelo de soja), em diferentes níveis (0, 10, 20 e 30\%), compondo

Tabela 1. Composição percentual das rações experimentais.

\begin{tabular}{|c|c|c|c|c|}
\hline \multirow[t]{2}{*}{ Alimentos } & $0 \%(\mathrm{~T} 1)$ & $10 \%(\mathrm{~T} 2)$ & $20 \%(\mathrm{~T} 3)$ & $30 \%(\mathrm{~T} 4)$ \\
\hline & $\mathrm{g}$ & $\mathrm{g}$ & $\mathrm{g}$ & $\mathrm{g}$ \\
\hline Celulose & 2,39 & 1,76 & 1,11 & 0,48 \\
\hline Farelo de milho & 29,09 & 24,49 & 19,35 & 14,90 \\
\hline Farelo de coco & 0,00 & 10,00 & 20,00 & 30,00 \\
\hline Farelo de soja & 53,35 & 48,80 & 44,65 & 40,22 \\
\hline L-Lisina & 0,52 & 0,52 & 0,52 & 0,52 \\
\hline BHT (butil hidroxi tolueno) & 0,02 & 0,02 & 0,02 & 0,02 \\
\hline DL-Metionina & 0,25 & 0,25 & 0,25 & 0,25 \\
\hline Oleo de soja & 4,60 & 4,70 & 4,94 & 4,95 \\
\hline Fosbical & 5,12 & 4,80 & 4,50 & 4,00 \\
\hline Calcário & 3,25 & 3,25 & 3,25 & 3,25 \\
\hline Sal & 0,50 & 0,50 & 0,50 & 0,50 \\
\hline Premix mineral e vitaminíco & 0,41 & 0,41 & 0,41 & 0,41 \\
\hline Alginato de sódio & 0,50 & 0,50 & 0,50 & 0,50 \\
\hline Total (gramas) & 100,00 & 100,00 & 100,00 & 100,00 \\
\hline
\end{tabular}


quatro rações completas, sendo uma testemunha, perfazendo quatro tratamentos e dez repetições (Tabela 1).

Para a elaboração das rações experimentais, as matériasprimas foram processadas individualmente em moinho para obter a mesma granulometria 0,42 mm (mash 40). Iniciou-se o experimento com a granulometria para as rações de $0,84 \mathrm{~mm}$ (mash 20), finalizando-o com 3,35 mm (mash 6).

\subsection{Análises químicas}

As análises dos teores de umidade, cinzas, proteína bruta e verdadeira foram realizadas segundo a AOAC (ASSOCIATION OF OFFICIAL ANALYTICAL CHEMISTS, 1995). Os carboidratos foram determinados por diferença. O valor calórico foi determinado a partir dos coeficientes calóricos correspondentes para carboidratos, proteínas e lipídios, respectivamente 4, 4 e 9 Kcal.g ${ }^{-1}$ (BRASIL, 1998).

A extração lipídica e a determinação de lipídios totais foram realizadas através do método Folch, Lees e Stanley (1957). O colesterol foi determinado por colorimetria segundo Bohac et al. (1988).

A esterificação dos ácidos graxos foi realizada segundo Hartman e Lago (1973).

\subsection{Análise cromatográfica dos ésteres metílicos de ácidos graxos}

O material foi injetado manualmente em cromatógrafo a gás (Gas Chromatograph - 5890 series II - Hewlett Packard), equipado com detector de ionização de chama, injetor splitless, utilizando uma coluna capilar DB-23 (60 m de comprimento, $0,25 \mathrm{~mm}$ de diâmetro e $0,25 \mu \mathrm{m}$ de espessura), sendo o gás de arraste o hélio, com uma vazão de $1,5 \mathrm{~mL} /$ minutos em modo de pressão constante.

As condições cromatográficas foram: temperatura da coluna programada, temperatura inicial $130{ }^{\circ} \mathrm{C} / 1$ minuto, elevando-se para $170{ }^{\circ} \mathrm{C}$ numa escala de $6,5^{\circ} \mathrm{C} /$ minuto; voltando a elevar-se para $215^{\circ} \mathrm{C}$, numa escala de $2,8^{\circ} \mathrm{C} /$ minuto; permanecendo nessa temperatura por 12 minutos, com uma elevação para $230^{\circ} \mathrm{C}$ numa escala de $40^{\circ} \mathrm{C} /$ minuto; e permanecendo nesta temperatura por mais 3 minutos. As temperaturas do injetor e detector foram 280 e $270{ }^{\circ} \mathrm{C}$, respectivamente. $\mathrm{O}$ volume de injeção foi de $0,3 \mu \mathrm{L}$. O tempo de análise cromatográfica foi de 38 minutos.

A identificação dos ácidos graxos foi realizada por comparação do tempo de retenção dos ácidos graxos das amostras com os padrões. Foram utilizados 37 padrões de ácidos graxos da Supelco $^{\mathrm{TM}}$ (37 compostos). A quantificação dos ácidos graxos foi realizada por normalização de área, expressando-se o resultado em porcentagem de área relativa.

\subsection{Análise estatística}

O delineamento experimental foi inteiramente casualizado e os dados obtidos foram submetidos à análise de variância em nível de $5 \%$ de probabilidade através do programa SAEG (Sistema para Análises Estatísticas e Genéticas). A comparação de médias entre os tratamentos foi realizada através do teste de Tukey ( $\mathrm{p}<0,05)$ (STEEL; TORRIE, 1984).

\section{Resultados e discussão}

Os teores de umidade, lipídios, cinzas, proteína bruta e verdadeira, carboidratos e valor calórico do filé nos diferentes tratamentos, estão apresentados na Tabela 2.

Observou-se diferença $(\mathrm{p}<0,05)$ entre T1 e T3, T2 e T3 para os teores de umidade; entre T2 e T3 para os teores de lipídios; T1 apresentou diferença, com relação aos demais tratamentos, no referente aos teores de carboidratos; e no que diz respeito aos teores de cinzas, foram observadas diferenças de $\mathrm{T} 1$ entre T3 e T4, e de T2 entre T3 e T4.

Os resultados encontrados para a umidade são semelhantes àqueles relatados por Ogawa e Maia (1999), quando descrevem que o músculo do pescado contém teores de umidade variando de 60 a 85\%. Leonhardt et al. (2006) apresentaram a composição do filé de duas espécies (tilápia-vermelha e tilápia-do-nilo)

Tabela 2. Composição Centesimal e valor calórico do filé de tilápia-do-nilo alimentada com dietas contendo diferentes níveis de farelo de coco.

\begin{tabular}{|c|c|c|c|c|c|}
\hline \multirow{2}{*}{$\begin{array}{c}\text { Composição centesimal } \\
\left.\text { (g.100 } \mathrm{g}^{-1} \text { de porção comestível }\right)^{\star}\end{array}$} & \multicolumn{5}{|c|}{ Tratamentos } \\
\hline & T1 (Controle; 0\%) & T2 (10\%) & T3 (20\%) & T4 (30\%) & $\mathrm{cv}(\%)$ \\
\hline Umidade & $78,09^{\mathrm{a}}( \pm 0,84)$ & $78,44^{\mathrm{a}}( \pm 0,52)$ & $74,83^{\mathrm{b}}( \pm 6,05)$ & $76,60^{\mathrm{ab}}( \pm 0,78)$ & 3,92 \\
\hline Proteína bruta (BU) & $18,08^{\mathrm{a}}( \pm 1,17)$ & $17,57^{\mathrm{a}}( \pm 0,84)$ & $18,65^{\mathrm{a}}( \pm 1,49)$ & $17,96^{\mathrm{a}}( \pm 1,22)$ & 8,16 \\
\hline Proteína bruta (BS) & $83,12^{\mathrm{a}}( \pm 3,85)$ & $82,1^{\mathrm{a}}( \pm 5,03)$ & $79,82^{\mathrm{a}}( \pm 5,00)$ & $77,85^{\mathrm{a}}( \pm 3,25)$ & 6,37 \\
\hline Proteína verdadeira (BU) & $16,5^{\mathrm{a}}( \pm 1,44)$ & $16,33^{\mathrm{a}}( \pm 1,31)$ & $15,64^{\mathrm{a}}( \pm 1,80)$ & $15,69^{\mathrm{a}}( \pm 2,07)$ & 10,38 \\
\hline Proteína verdadeira (BS) & $75,05^{\mathrm{a}}( \pm 4,34)$ & $75,34^{\mathrm{a}}( \pm 6,77)$ & $68,24^{\mathrm{a}}( \pm 7,33)$ & $67,25^{\mathrm{a}}( \pm 6,66)$ & 8,70 \\
\hline Carboidratos (BU) & $0,78^{\mathrm{a}}( \pm 0,11)$ & $0,22^{\mathrm{b}}( \pm 0,18)$ & $0,31^{\mathrm{b}}( \pm 0,32)$ & $0,00^{\mathrm{b}}$ & 12 \\
\hline Carboidratos (BS) & $3,56^{\mathrm{a}}( \pm 0,42)$ & $1,04^{\mathrm{b}}( \pm 0,84)$ & $1,37^{\mathrm{b}}( \pm 1,43)$ & $0,00^{\mathrm{b}}$ & 26,62 \\
\hline Cinzas (BU) & $1,23^{\mathrm{b}}( \pm 0,05)$ & $1,21^{\mathrm{b}}( \pm 0,06)$ & $1,45^{\mathrm{a}}( \pm 0,11)$ & $1,47^{\mathrm{a}}( \pm 0,07)$ & 6,08 \\
\hline Cinzas (BS) & $5,61^{\mathrm{b}}( \pm 0,04)$ & $5,55^{\mathrm{b}}( \pm 0,35)$ & $6,18^{\mathrm{a}}( \pm 0,36)$ & $6,25^{\mathrm{a}}( \pm 0,29)$ & 5,03 \\
\hline Calorias (Kcal) & $87,86^{\mathrm{a}}( \pm 0,52)$ & $89,23^{\mathrm{a}}( \pm 2,50)$ & $86,41^{\mathrm{a}}( \pm 1,50)$ & $88,09^{\mathrm{a}}( \pm 4,16)$ & 2,59 \\
\hline
\end{tabular}

*Analisadas 20 amostras com 5 repetições por tratamento, com a média e o desvio padrão entre parênteses.Valores na mesma linha com letras (a, b) diferentes significam diferenças estatisticamente significativas $(\mathrm{p}<0,05) . \mathrm{BU}=$ Base úmida. $\mathrm{BS}=$ Base seca. 
demonstrando valores de 79,20 e 78,43\%. Justi et al. (2005), ao analisarem a influência da temperatura $\left(23,26,29\right.$ e $\left.32^{\circ} \mathrm{C}\right)$ sobre a composição centesimal de tilápia-do-nilo, detectaram teores de 77,31 a 78,46\% no referente à umidade.

Segundo Visentainer et al. (2005), o teor de cinzas observado em filés de tilápia submetidas a diferentes níveis de óleo de linhaça na ração foram de 0,9 a 1,1\%. Minozzo (2005), ao estudar a composição centesimal de tilápia-do-nilo, observou variações nos teores de cinzas de 0,7 a $3,1 \%$. Os valores obtidos no presente trabalho variaram de 1,21 a $1,47 \%$.

Santos et al. (2000) classificam como magro o peixe que possui no máximo 2,5\% de gordura. Essa classificação quanto ao teor de gordura é de grande importância, pois o teor de gordura pode influenciar diretamente a performance produtiva e a aceitação do peixe pelo consumidor, além de alterar a palatabilidade da carne. Os teores lipídicos observados estão abaixo de 2,5\%.

No que diz respeito aos teores de proteínas bruta, Leonhardt et al. (2006) encontraram teores variando de 18,47 a 19,33\%. Segundo Visentainer et al. (2005), o teor de proteína observado em filés de tilápia submetidas a diferentes níveis de óleo de linhaça na ração apresentou-se entre 19,8 e 20,9\%. Os valores obtidos no presente trabalho variaram de 17,57 a 18,65\%.

Os resultados obtidos referentes ao teor de colesterol para o filé estão apresentados da Tabela 3. Observa-se que houve diferença $(p<0,05)$ entre os tratamentos, exceto entre T2 e T3; e entre T1 e T2. Aqueles animais que consumiram ração com o maior percentual de inclusão do farelo de coco apresentaram os maiores valores de colesterol no filé.

Os resultados encontrados são superiores (variando de 91,06 a $162 \mathrm{mg} .100 \mathrm{~g}^{-1}$ ) àqueles relatados por Ferreira et al. (2007), que encontraram o teor de colesterol de $33 \mathrm{mg} .100 \mathrm{~g}^{-1}$ para o filé de tilápia-do-nilo in natura criada em tanque de terra e alimentada com ração comercial. Visentainer et al. (2005) observaram que o teor de colesterol encontrado em filé de tilápia submetida a diferentes níveis de óleo de linhaça na ração apresentou variação de 58,3 a $75,5 \mathrm{mg} \cdot 100 \mathrm{~g}^{-1}$ de tecido muscular.

No referente aos ácidos graxos, foram identificados 15 ácidos graxos (Tabela 4) presentes no filé e se observou diferença estatisticamente significativa $(p<0,05)$ entre os tratamentos referentes aos seguintes ácidos graxos: $\mathrm{C}_{10: 00^{\circ}}, \mathrm{C}_{12: 0^{\prime}}$, $\mathrm{C}_{14: 0^{\prime}}, \mathrm{C}_{18: 1}, \mathrm{C}_{18: 3}$ (gama), $\mathrm{C}_{20: 3}, \mathrm{e}_{22: 6}$.

Tabela 3. Teores de colesterol em filé de tilápia-do-nilo alimentadas com rações contendo diferentes níveis de farelo de coco.

\begin{tabular}{lcc}
\hline \multirow{2}{*}{ Tratamentos } & \multicolumn{2}{c}{ Teores $\left(\mathrm{mg} .100 \mathrm{~g}^{-1}\right)^{\star}$} \\
\cline { 2 - 3 } & Base úmida & Base seca \\
\hline T (Controle; 0\%) & $91,06^{\mathrm{c}}( \pm 2,88)$ & $415,28^{\mathrm{b}}( \pm 21,45)$ \\
T2 $(10 \%)$ & $98,70^{\mathrm{bc}}( \pm 1,92)$ & $455,39^{\mathrm{b}}( \pm 16,70)$ \\
T3 $(20 \%)$ & $109,86^{\mathrm{b}}( \pm 3,08)$ & $481,04^{\mathrm{b}}( \pm 40,53)$ \\
T4 (30\%) & $162,00^{\mathrm{a}}( \pm 14,25)$ & $696,04^{\mathrm{a}}( \pm 56,79)$ \\
cV (\%) & 6,31 & 7,55 \\
\hline
\end{tabular}

*Analisadas 20 amostras com 5 repetições por tratamento, com a média e o desvio padrão entre parênteses. Valores na mesma coluna com letras $(a, b, c)$ diferentes significam diferenças estatisticamente significativas $(\mathrm{p}<0,05)$.
Justi et al. (2005), ao analisarem a influência da temperatura sobre o perfil de ácidos graxos, não observaram diferenças significativas entre os tratamentos. Aiura e Carvalho (2004), ao avaliarem os teores de ácidos graxos do músculo de tilápia híbrida (Oreochromis niloticus $\times$ O. aureus) alimentada com várias fontes de lipídios, verificaram que a composição refletiu a composição do lipídio presente na alimentação.

Dentre os ácidos graxos saturados totais, encontrou-se uma variação de 45,69 a 57,32\%, havendo predominância do $\mathrm{C}_{16: 0}$, em relação aos demais ácidos graxos, nos tratamentos 2 $(19,99 \%), 3(19,70 \%)$ e $4(18,76 \%)$. Enquanto no tratamento 1, a predominância foi dos ácidos $\mathrm{C}_{12: 0}-21,09 \%$ e $\mathrm{C}_{16: 0}-20,59 \%$.

O ácido palmítico $\left(\mathrm{C}_{16: 0}\right)$ também foi observado em maiores quantidades entre os saturados por Moreira et al. (2001) em três espécies brasileiras de peixe de água doce, em tilápia por Aiura e Carvalho (2004) e Justi et al. (2003). Maina et al. (2003), estudando a composição corporal de ácidos graxos de tilápias-do-nilo (Oreochromis niloticus) alimentadas com dietas à base de torta de girassol e óleo de milho, em substituição à farinha de peixe, observaram teor elevado do ácido palmítico $\left(\mathrm{C}_{16: 0}\right)-31,3 \%$.

Com relação ao ácido esteárico $\left(\mathrm{C}_{18: 0}\right)$, o qual apresentou teores de 5,95 a 6,97\% entre os tratamentos, Denke e Grundy (1991) referem que a gordura rica neste ácido não eleva os níveis de colesterol total em comparação com a dieta rica em ácido oleico.

Os valores referentes aos AGMI totais (11,57 a 17,23\%) foram inferiores aos relatados por Méndez et al. (1996) para corvina branca e para "palometa", 39,0 e 41,9\%, respectivamente. Os ácidos graxos monoinsaturados têm um efeito hipocolesterolêmico intermediário (KRIS-ETHERTON; YU, 1997). Os teores totais dos ácidos poli-insaturados (21,66 a 23,99\%) não apresentaram variações significativas entre os tratamentos. Nova, Godoy e Aldrigue (2000) detectaram um teor de 11,62\%, para tilápia.

$\mathrm{O}$ ácido araquidônico $\left(\mathrm{C}_{20: 4}\right)$ apresentou teores de $0,82 \mathrm{a}$ $1,16 \%$. Nova, Godoy e Aldrigue (2000) detectaram em tilápia um teor de 3,21\%. Este ácido é considerado importante, pois está envolvido no mecanismo da agregação plaquetária. À medida que é liberado dos fosfolipídios da membrana da plaqueta, é utilizado na formação de prostanóides pela ação da cicloxigenase, com efeito pró-agregatório. Esta propriedade é modulada pela concentração de ácidos graxos poli-insaturados com 20 e 22 átomos de carbono na molécula (MINOZZO, 2005).

Nova, Godoy e Aldrigue (2000) detectaram em tilápia teor de DHA de 4,46\%. Oliveira et al. (2004) demonstram valores de DHA de $0,60 \%$. Os estudos acima relatados indicam valores mais elevados aos nossos que apresentaram teores de DHA variando de 0,49 a $1,13 \%$. Os ácidos graxos poli-insaturados $C_{20: 4} \omega-6 \mathrm{e}$ ${ }_{0} \mathrm{C}_{22: 6} \omega-3$ (DHA) são componentes estruturais predominantes da substância cinzenta do cérebro e da retina e, dessa forma, devem fazer parte da dieta da mãe para estarem disponíveis ao feto (tecido placentário) e ao recém-nascido (amamentação) (SIMOPOULOS, 1991). O ácido cis, cis, cis, cis, cis, cis - 4, $7,10,13,16,19$ - docosaesanoico (DHA) da série $\omega$ - 3 apresentou um aumento do considerável (T2 - 0,73\%; T3 - 1,13\%; e T4 $1,07 \%)$ em relação ao controle (T1 - 0,49\%). 
Tabela 4. Perfil dos ácidos graxos presentes nos filés, valores expressos em percentagem de área relativa.

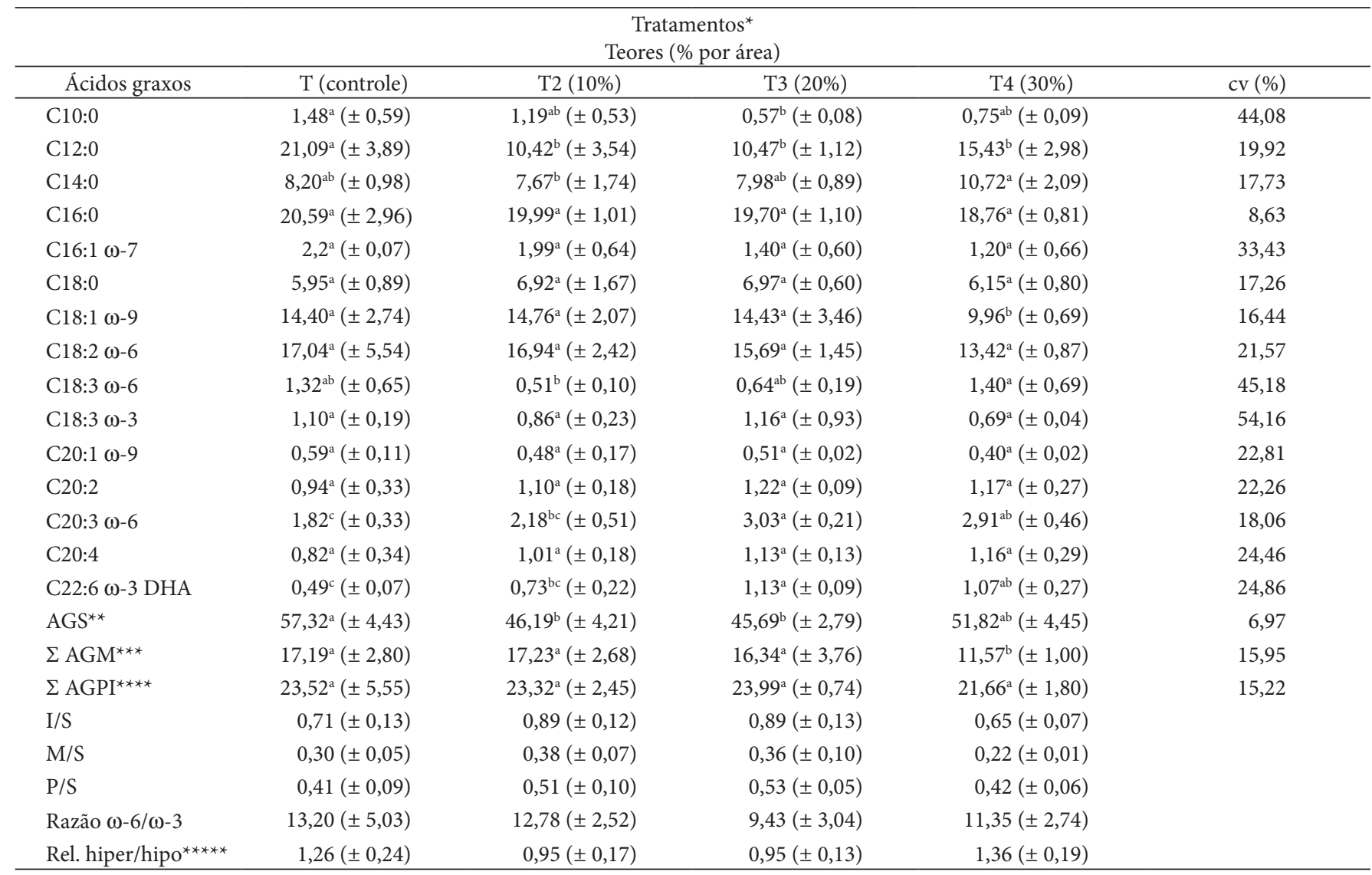

*Analisadas 20 amostras com 5 repetições por tratamento, com a média e o desvio padrão entre parênteses; Valores na mesma linha com letras (a,b, c) diferentes significam diferença estatística $(\mathrm{p}<0,05) . \sum \mathrm{AGS}^{* *}=$ Somatório dos Ácidos graxos Saturados. $\sum \mathrm{AGM}^{* * *}=$ Somatório dos Ácidos graxos Monoinsaturados. $\sum$ AGPI ${ }^{* * * *}=$ Somatório dos Ácidos graxos Poli-insaturados. I/S = Insaturados/Saturados M/S = Monoinsaturados/Saturados P/S = Poli-insaturados/Saturados Rel. Hiper/Hipo***** $=$ Relação ácido graxo hipercolesterolêmico/ hipocolesterolêmico = ácido graxo hipercolesterolêmico (C14:0 + C12:0 + C16:0) / ácido graxo hipocolesterolêmico (monoinsaturado + poli-insaturados).

O ácido linoleico (LA) é precursor do ácido araquidônico (AA, 20:4 $\omega-6$ ), componente utilizado na síntese de prostaglandinas e importante para o crescimento fetal; e o ácido a-linolênico (LNA) é o precursor dos ácidos graxos de cadeia longa $\omega-3$, tais como EPA e DHA (STEVANATO et al., 2007). Estes ácidos se destacam por apresentarem diversos efeitos benéficos à saúde humana, como diminuição dos riscos de doenças cardiovasculares, diminuição nas taxas de colesterol no sangue, prevenção de câncer e benefícios à gravidez e saúde materno-infantil (STEVANATO et al., 2007). O ácido a-linolênico apresentou teores de 0,69 a 1,16\%.

A relação poli-insaturados/saturados $(\mathrm{P} / \mathrm{S})$ verificada foi de 0,41 a 0,53 , demonstrando valores próximos da faixa mínima recomendada pelo British Department of Health para a dieta total, que é de 0,45 (MENEZES, 2006). A relação P/S é de extrema importância na elaboração de dietas, pois um excesso de ácido linoléico irá competir pelas dessaturases, comprometendo o teor de ácido graxo da série $\omega-3$, tendo como possível consequência uma baixa produção de ácido eicosapentanóico (KRAUSS et al., 2000). Freitas et al. (2002) chamam a atenção para a inadequação de dietas que levam em conta teores isolados de lipídios, relação $\mathrm{P} / \mathrm{S}$, ácidos graxos saturados ou poli-insaturados.

\section{Conclusões}

O farelo de coco pode ser utilizado na alimentação de tilápia, pois não afeta a composição centesimal, o teor de colesterol e o teor de ácidos graxos do filé, mantendo o valor nutricional e a mesma qualidade para o consumo humano.

\section{Agradecimentos}

Ao Conselho Nacional de Desenvolvimento Científico e Tecnológico (CNPq) e a João Gomes da Costa (Empresa Brasileira de Pesquisa Agropecuária - Embrapa).

\section{Referências bibliográficas}

AIURA, F. S.; CARVALHO, M. R. B. Composição em ácidos graxos e rendimento de filé de tilápia do Nilo (Oreochromis niloticus) alimentada com dietas contendo tanino. RPCV, v. 99, n. 550, p. 93-98, 2004.

ALBUQUERQUE, W. F.; ZAPATA, J. F. F.; ALMEIDA, R. S. Estado de frescor, textura e composição muscular da tilápia-do-Nilo abatida com dióxido de carbono e armazenada em gelo. Revista Ciência Agronômica, v. 35, Número Especial, p. 264-271, out. 2004.

ASSOCIATION OF OFFICIAL ANALYTICAL CHEMISTS - AOAC. Analytical Chemistry. 16 ed. Arlington, 1995. v. 2, p. 1-30. 
BOHAC, C. E. et al. Assessement of metodologies for colorimetric cholesterol assay of meats. Journal Food Science, v. 53, p. 1642, 1988.

BOSCOLO, W. R.; HAYASHI, C.; MEURER, F. Farinha de Varredura de Mandioca (Manihot esculenta) na Alimentação de Alevinos de Tilápia do Nilo (Oreochromis niloticus L.). Revista Brasileira de Zootecnia, v. 31, n. 2, p. 546-551, 2002.

BRAGA, C. V. P. et al. Efeito da inclusão do farelo de coco em rações para poedeiras comerciais. Revista Brasileira de Zootecnia, v. 34, n. 1, p. 76-80, 2005.

BRASIL. Ministério da Saúde. Agência Nacional de Vigilância Sanitária - ANVISA. Leis, decretos, etc. Portaria $n^{\circ} 33 / 98$. Diário Oficial, Brasília, 30 de março de 1998, seção I, n 60-E, p. 5-6. (Adota os valores constantes das tabelas do anexo desta portaria como níveis de IDR (Ingestão Diária Recomendada) para as vitaminas, minerais e proteínas).

CAMPO, L. F. C. Tilápia Roja 2006, una evolución de 25 años de la incertidumbre al exito. Manual de Manejo Industrial de la tilapia Roja, v. 27, n. 8, p. 124, 2006. Disponível em: <http//ag.arizona. edu/azaqua/ista/Colombia/TILAPIAROJA2006.pdf > . Acesso em: 15 dez. 2007.

DENKE, M. A.; GRUNDY, S. M. Effects of fats hing in stearic acid on lipid and lipoprotein concentrations in men. American Journal of Clinical Nutrition, v. 54, p. 1036-1040, 1991.

FERREIRA, M. W. et al. Efeito dos métodos de cocção sobre a composição química e perfil lipídico de filés de tilápia do Nilo (Oreochromis niloticus Linnaeus, 1757). Ciência e Agrotecnologia, v. 31, n. 3, p. 798-803, maio/jun. 2007.

FOLCH, J.; LEES, M.; STANLEY, G. H. S. A simple method for the isolation and purification of total lipidis from animal tissues. Journal of Biological Chemistry, v. 226, n. 1, p. 497-509, 1957.

FOOD AND AGRICULTURE ORGANIZATION - FAO. Disponível em: <http//www.fao.org. Acesso em: 29 Abr. 2003.

FREITAS, A. S. et al. Teores de lipídeos totais, ácidos graxos e colesterol em resíduos desidratados de camarão-sete-barbas (Xiphopenaeus kroyeri HELLER, 1862) capturado no estado do Rio de Janeiro. Boletim Centro de Pesquisa de Processamento de Alimentos, v. 20, n. 2, p. 355-362, 2002.

FURUYA, W. M. et al. Fitase na Alimentação da Tilápia do Nilo (Oreochromis niloticus). Desempenho e Digestibilidade. Revista Brasileira de Zootecnia, v. 30, n. 3, p. 924-929, 2001. (Suplemento 1).

HARTMAN, L.; LAGO, B. C. A. Rapid preparation of fatty methyl esters from lipids. Laboratory Practice, v. 22, p. 475 - 77, 1973.

JUSTI, K. C. et al. Efeito da temperatura da água sobre desempenho e perfil de ácidos graxos de tilápia do Nilo (Oreochromis niloticus). Maringá, v. 27, n. 4, p. 529-534, Oct./Dec. 2005.

JUSTI, K. C. et al. The influence of feed supply time on the fatty acid profile of Nile tilapia (Oreochromis niloticus) fed on a diet enriched with n-3 fatty acids. Food Chemistry, v. 80, p. 489-493, 2003.

KRAUSS, R. M. et al. Dietary guidelines: revision 2000: a statement for healthcare professionals from the nutrition committee of the American heart Association. Circulation, v. 102, n. 18, p. 2284-2299, 2000.

KRIS-ETHERTON, P.; YU, S. Individual fatty acids effects on plasma lipids and lipoproteins; human studies. American Journal Clinical Nutrition, v. 65, Suppl., p. 1628-1644, 1997.

LEONHARDT, J. H. et al. Características morfométricas, rendimento e composição do filé de tilápia do Nilo, Oreochromis niloticus, da linhagem tailandesa, local e do cruzamento de ambas. Semina: Ciências Agrárias, v. 27, n. 1, p. 125-132, jan./mar. 2006.

MAINA, J. G. et al. Partial replacement of fishmeal with sunflower cake and corn oil in diets for tilapia Oreochromis niloticus (Linn): effect on whole body fatty acids. Aquaculture Research, v. 34, p. 601-608, 2003.
MÉNDEZ, E. et al. Lipid content and fatty acid composition of fillets of six fishes from the Rio de La Plata. Journal of Food Composition and Analysis, v. 9, p. 163-170, 1996.

MENEZES, M. E. S. Valor nutricional de espécies de peixes (água salgada e estuário) do estado de Alagoas. $113 \mathrm{f}$. Dissertação (Mestrado) - Instituto de Química e Biotecnologia, Universidade Federal de Alagoas, Maceió, 2006.

MINOZZO, M. G. Elaboração de patê cremoso a partir de filé de tilápia do Nilo (Oreochromis niloticus) e sua caracterização físico-químico microbiológica e sensorial. $127 \mathrm{f}$. Dissertação (Mestrado em Tecnologia de Alimentos) - Universidade Federal do Paraná, Curitiba, 2005.

MOREIRA, A. B. et al. Fatty acids profile and cholesterol contents of three brazilian Brycon freshwater fishes. Journal of Food Composition Analysis, v. 14, p. 565-74, 2001.

NOVA, C. M. V. M. V.; GODOY, H. T.; ALDRIGUE, M. L. Composição de ácidos graxos dos lipídeos totais de tilápia (Oreochromis niloticus) e pargo (Lutjanus purpureus). In: CONGRESSOS BRASILEIROS DE CIÊNCIA E TECNOLOGIA DE ALIMENTOS, 17, 2000, Fortaleza.

NOVA, C. M. V. M. V.; GODOY, H. T.; ALDRIGUE, M. L. Composição química, teor de colesterol e caracterização dos lipídeos totais de tilápia (Oreochromis niloticus) e pargo (Lutjanus purpureus). Ciência e Tecnologia de Alimentos, v. 25, n. 3, Jul./Set. 2005.

OGAWA, M.; MAIA, E. L. Manual de pesca: ciência e tecnologia do pescado. São Paulo: Varela, 1999. v. 1, p. 430.

OLIVEIRA, N. M. S. et al. Perfil de ácidos graxos em filés de tilápia (Oreochromis niloticus) submetidos a tratamentos de sanificação. In: CONGRESSO BRASILEIRO DE CIÊNCIA E TECNOLOGIA DE ALIMENTOS, 19, 2004, Recife, Pernambuco.

RIBEIRO, R. P.; HAYASHI, C.; FURUYA, W. M. Curso de piscicultura: criação racional de tilápias. Maringá: FADEC, 1995. 23 p.

SANTOS, A. B. et al. Composição química e rendimento do filé da Traíra (Hoplias malabaricus). Revista da Faculdade de Zootecnia, Veterinária e Agronomia Uruguaiana, v. 7, n. 1, p. 33-39, 2000.

SIMOPOULOS, A. C. Omega-3 fatty acids in health and disease and in growth and development. American Journal of Clinical Nutrition, v. 54, n. 3, p. 438-463, 1991.

SOUZA, M. L. R. et al. Defumação da Tilápia do Nilo (Oreochromis niloticus) Inteira Eviscerada e Filé: Aspectos Referentes às Características Organolépticas, Composição Centesimal e Perdas Ocorridas no Processamento. Revista Brasileira de Zootecnia, v. 33, n.1, p. 27-36, 2004.

SOUZA, M. L. R.; MARANHÃO, T. C. F. Rendimento de carcaça, filé e subprodutos da filetagem da tilápia do Nilo, Oreochromis niloticus (L), em função do peso corporal. Acta Scientiarum, v. 23, n. 4, p. 897-901, 2001.

SOUZA, N. E. et al. Composição química, perfil de ácidos graxos e quantificação dos ácidos $\alpha$-linolênico, eicosapentaenóico e docosahexaenóico em vísceras de tilápias (Oreochromis niloticus). Acta Scientiarum Technology, v. 27, n. 1, p. 73-76, Jan./June, 2005.

STEEL, R. G. D.; TORRIE, S. H. Principles and procedures of statistics: a biometrical approach. 2 ed. Auckland: Mc Graw-Hill International, 1984. p. 633.

STEVANATO, F. B. et al. Avaliação química e sensorial da farinha de resíduo de tilápias na forma de sopa. Ciência e Tecnologia de Alimentos, v. 27, n. 3, p. 567-571, jul./set. 2007.

VISENTAINER, J. V. et al. Relação entre teores de colesterol em filés de tilápias e níveis de óleo de linhaça na ração. Ciência e Tecnologia de Alimentos, v. 25, n. 2, p. 310-314, abr./jun. 2005. 